\title{
Factors associated with pelvic organ prolapse: a prospective study in a tertiary care hospital in Northern India
}

\author{
Deepti Verma* \\ Department of Obstetrics and Gynecology, Mayo Institute of Medical Sciences, Barabanki, Uttar Pradesh, India
}

Received: 24 March 2016

Accepted: 23 April 2016

*Correspondence:

Dr. Deepti Verma,

E-mail: drdeepti86@gmail.com

Copyright: $\odot$ the author(s), publisher and licensee Medip Academy. This is an open-access article distributed under the terms of the Creative Commons Attribution Non-Commercial License, which permits unrestricted non-commercial use, distribution, and reproduction in any medium, provided the original work is properly cited.

\section{ABSTRACT}

Background: Pelvic organ prolapse (POP) is a common health problem affecting the multiparous women. Various demographic and social factors are the underlying cause for POP.

Methods: This is a prospective study on 100 patients of pelvic organ prolapse attending the gynecological OPD of a tertiary care institute in Northern India. A thorough history was taken and a complete examination was done. The data was collected and analyzed.

Results: The findings of the study revealed that the mean age of the patient was 49.45 years with $84 \%$ of the patient above 35 years. Illiteracy was present in $54 \%$ of the patients. The mean age of marriage was 20.02 years and $63 \%$ of the women in the study group had their first pregnancy before 20 years of age. Majority of patients $(72 \%)$ had 2 or more deliveries at home, attended by untrained birth attendant. Parity of more than four was present in $70 \%$ patients. A large percentage of patients (78\%) resumed their work within one month of delivery. Mean age of onset of POP was 47.79 years and mean duration of POP was 7.2 years before consulting a doctor.

Conclusions: Early marriage, pregnancy at an early age, deliveries at home, multiple childbirth, and inadequate rest and nutrition in the postpartum period is the key underlying factors leading to pelvic organ prolapse.

Keywords: Pelvic organ prolapse, Pregnancy

\section{INTRODUCTION}

Pelvic organ prolapse (POP) is a common health problem affecting up to $40 \%$ of multi para women over 35 years old. ${ }^{1}$ The life-time risk for women to undergo surgery for the management of POP is about $11 \%$ and $30 \%$ of these women will need additional surgery because of prolapse recurrence. $^{2}$

The risk of POP increases with the number of vaginal births and is higher in older and obese women. POP has significant negative effects on a woman's quality of life, ranging from physical discomfort, psychological and sexual complaints to occupational and social restrictions. ${ }^{3}$ POP is defined as the descent of one or more of the pelvic organs. Anterior vaginal wall prolapse contains the bladder and/or urethra (cystocele, urethrocele). Apical prolapse entails either the uterus or post-hysterectomy vaginal cuff. Posterior vaginal wall prolapse contains the rectum but can also include the small or large bowel (rectocele, enterocele).

Pelvic organ prolapse is one of the most common gynecological problems in India. Number of national and international studies has shown that pelvic organ prolapse is a second major morbidity problem among the women during their reproductive period. It is a preventable and curable disease and it is reported to be second priority in surgery, the operation followed by hysterectomy. Thus it is important and necessary for researchers to study it and provide appropriate and adequate statistics and status of this disease to policy makers and planners for providing effective solution. 


\section{METHODS}

This was a prospective study in the patients having pelvic organ prolapse and attending the gynecological OPD of the Mayo institute of medical sciences, Barabanki, Uttar Pradesh, India. A thorough history was taken and complete examination was done in all the patients. A total of 100 women with pelvic organ prolapse were included in the study over one year interval.

The entire data was evaluated using statistical analysis software package (SPSS) software.

\section{RESULTS}

The results revealed that the majority of patients in the study group were above 35 years of age (84\%).

The mean age of the patients was 49.45 years. The entire patient population was housewife, with $37 \%$ of them also working in the fields along with the household chores.

Illiteracy was present in $54 \%$ patients, with rest $46 \%$ patients being literate with maximum education upto class XII.

The major source of income for more than half of the respondents was agriculture $(72.6 \%)$ and two third of respondents were living in joint families $(84.2 \%)$, with an average of more than 6 members in the family.

The major factors affecting the presence of pelvic organ prolapse are the early age of marriage, early and frequent childbirths and multiple deliveries. This was depicted in the result of our study.

This study showed that $56 \%$ of the patients were married by 20 years of age (Table 1$)$. The mean age of marriage was 20.02 years, with the minimum age of marriage being 11 years and maximum age was 27 years.

Table 1: Age distribution of the study group at the time of marriage.

\begin{tabular}{|lllll|}
\hline $\begin{array}{l}\text { Age at the time of } \\
\text { marriage (years) }\end{array}$ & $\begin{array}{l}\text { Number of } \\
\text { patients }\end{array}$ & Mean \\
\hline$<16$ & 10 & & & \\
\hline $17-20$ & 46 & 20.02 & 11 & 27 \\
\hline $21-25$ & 40 & & & \\
\hline$>26$ & 4 & & & \\
\hline
\end{tabular}

Majority of patients were pregnant $(63 \%)$ before 20 years of age (Table 2). Out of these $4 \%$ of women were pregnant before the age of 16 years. In this study, the mean age of the first child birth of the patients was 19.58 years. Prolapse was directly associated with parity, with $70 \%$ of patients having parity more than four (Table 4). Of all the women, $72 \%$ women had two or more deliveries at home, attended by untrained birth attendant.
A large percentage $(78 \%)$ of patients resumed their household and agricultural chores within one month of the childbirth.

Table 2: Age at the time of first pregnancy.

\begin{tabular}{|lllll|}
\hline $\begin{array}{l}\text { Age at the time } 0 \\
\text { first delivery }\end{array}$ & $\begin{array}{l}\text { Number of } \\
\text { patients }\end{array}$ & & Mean & \\
\hline$<16$ & 4 & & & \\
\hline $17-20$ & 59 & 19.58 & 15 & 27 \\
\hline $21-25$ & 34 & & & \\
\hline$>26$ & 3 & & & \\
\hline
\end{tabular}

Table 3: Age of the respondents at the time of the onset of prolapse.

\begin{tabular}{|c|c|c|c|}
\hline $\begin{array}{l}\text { Age at the time of } \\
\text { onset of prolapse }\end{array}$ & $\begin{array}{l}\text { Number of } \\
\text { patients }\end{array}$ & & Mean \\
\hline$<16$ & 0 & & \\
\hline $17-20$ & 0 & & \\
\hline $21-25$ & 2 & 47.79 & $25 \quad 61$ \\
\hline $26-30$ & 2 & & \\
\hline $31-35$ & 13 & & \\
\hline$>36$ & 83 & & \\
\hline
\end{tabular}

Table 4: Parity of the respondents in the study group.

\begin{tabular}{|lllll|}
\hline Parity & $\begin{array}{l}\text { Number of } \\
\text { patients }\end{array}$ & $\begin{array}{l}\text { Mean } \\
\text { Parity }\end{array}$ & $\begin{array}{l}\text { Minimum } \\
\text { Parity }\end{array}$ & $\begin{array}{l}\text { Maximum } \\
\text { Parity }\end{array}$ \\
\hline 1 & 0 & & & \\
\hline 2 & 2 & 4.79 & 2 & 12 \\
\hline 3 & 28 & & & \\
\hline$>4$ & 70 & & & \\
\hline
\end{tabular}

The mean age of onset of uterovaginal prolapse in the study group was 47.79 years (Table 3). Maximum patients $(83 \%)$ had onset of prolapse after 36 years of age. None of the patient has the onset of prolapse before 20 years of age, indicating the fact that the incident of prolapsed greatly increases with increasing parity. In the study group, $76 \%$ patients had achieved menopause at the time of study.

This study also showed that the patients were having prolapse since a mean duration of 7.2 years. More than half of the patients $(52 \%)$ patients were suffering from the pelvic organ prolapse for more than 5 years, before consulting a doctor or a hospital. A total of $10 \%$ patients were having the problem for more than 10 years, and had no prior consultation with any doctor, indicating unawareness and negligence.

The major symptoms of the patients in the study group were: something coming out of the vagina (77\%), difficulty in micturition (16\%) and bleeding from vagina $(7 \%)$. Various factors were found to be associated with the development of the uterovaginal prolapse. Major factors were early marriage before 20 years $(56 \%)$, first child birth before 20 years of age $(63 \%)$, deliveries at 
home $(72 \%)$ and number of vaginal deliveries more than four $(70 \%)$. All the patients with pelvic organ prolapse underwent vaginal hysterectomy with or without anterior colporrhaphy and pelvic floor repair at our center.

\section{DISCUSSION}

Pelvic organ prolapse is one of the major cause of morbidity in women, especially the post-menopausal women, affecting the quality of life and leading to major surgery. Globally, prevalence of uterine prolapse is 15 to $25 \%$ amongst women above 20 years of age. ${ }^{4}$

In our study also, the incidence of prolapse was high in women above 35 years of age, with $83 \%$ patients developing prolapse after 35 years of age. Of these, $52 \%$ patients were suffering from the prolapse from more than 5 years and $10 \%$ patients were suffering from prolapse from more than 10 years. In the study done by Bijalwal RP et al, more than $75 \%$ of women suffering from the pelvic organ prolapse for more than 5 years. ${ }^{4}$ This indicates the ignorance in terms of recognizing the problem and seeking medical attention for the same. Illiteracy and poor family socio-economic status was the contributory factor for this ignorance.

The findings of the study revealed that there is significant degree of association with the type of delivery. The study indicated that $72 \%$ women with pelvic organ prolapse had two or more unsupervised deliveries at home. Similar results were found in another community based study, in which the $66 \%$ patients of the uterovaginal prolapse had two or more deliveries at home. ${ }^{4}$ This indicates that the unsupervised labour, prolonged labour duration and unattended delivery leads to extensive damage to the pelvic floor muscles, supporting ligaments of the uterus and thus leads to greater incidence of pelvic organ prolapse.

In our study, early marriage (before or at 20 years of age) was one of the contributing factor for pelvic organ prolapse. Earlier studies done by Bijalwan RP et al and Prasad DP also attribute early marriage and pregnancy at an early age to be the major associated factors with pelvic organ prolapse. ${ }^{4,5}$
Early marriage relates directly to increased parity, lower literacy status and hence is the major social cause for pelvic organ prolapse, as found in other studies also.

\section{CONCLUSION}

Pelvic organ prolapse is the disease due to ignorance and unawareness. Incidence of pelvic organ prolapse can be reduced by promoting institutional deliveries, awareness about the benefits of adequate post-partum rest and nutrition, and effective contraception to avoid repeated child births. Contact with health personnel's at the early stages of prolapse should be encouraged. Extensive information, preventive programs and early management of pelvic organ prolapse will be the key to reduce this major health problem.

\section{Funding: No funding sources Conflict of interest: None declared Ethical approval: Not required}

\section{REFERENCES}

1. Hove SMC, Al PG, Eijkemans MJ, SteegersTheunissen RP, Burger CW, Vierhout ME. The prevalence of pelvic organ prolapse symptoms and signs and their relation with bladder and bowel disorders in a general female population. Int Urogynecol. J Pelvic Floor Dysfunct. 2009;20(9):1037-45.

2. Olsen AL, Smith VJ, Bergstrom JO, Colling JC, Clark AL. Epidemiology of surgically managed pelvic organ prolapse and urinary incontinence. Obstet Gynecol. 1997;89(4):501-6.

3. Blandon RE, Bharucha AE, Melton LJ 3rd, Schleck CD, Babalola EO, Zinsmeister AR, Gebhart JB. Incidence of pelvic floor repair after hysterectomy: a population-based cohort study. Am J Obstet Gynecol. 2007;197(6):664.1-7.

4. Bijalwan RP, Bhagavatula M, Semwal VD, Rawat P, Anand V. Morbidity of uterine prolapse among the women in Chakrata block of Dehradun district. Indian J Comm Health. 2015;27(1);103-9.

5. Prasad DP. A study of prevalence and associated factors of uterus prolapse in Doti district of Nepal. Indian Journal of Public Health Research and Development 2013;4(3):53-7.

Cite this article as: Verma D. Factors associated with pelvic organ prolapse: a prospective study in a tertiary care hospital in Northern India. Int $\mathbf{J}$ Reprod Contracept Obstet Gynecol 2016;5:1862-4. 